\title{
Closing the Serological Gap in the Antiphospholipid Syndrome: The Value of "Non-criteria" Antiphospholipid Antibodies
}

\author{
Navid Zohoury, Maria Laura Bertolaccini, Jose Luis Rodriguez-Garcia, Zakera Shums, \\ Oier Ateka-Barrutia, Maurizio Sorice, Gary L. Norman, and Munther Khamashta
}

ABSTRACT. Objective. Most clinicians use the 2006 Sydney classification criteria to evaluate patients suspected of having antiphospholipid syndrome (APS). Although sensitive and specific for APS, many patients fulfilling clinical criteria for the syndrome are persistently negative for the specific serological tests ("laboratory criteria"). These "seronegative APS" (SN-APS) patients can go undiagnosed and untreated until they experience serious clinical events. This study's objective was to describe antibody profiles of SN-APS patients using non-criteria markers, assess the clinical utility of these markers separately and in combination, and suggest incorporation into guidelines for patients suspected of APS.

Methods. We categorized 175 consecutive patients suspected of APS into 2 subgroups: 107 fulfilling Sydney APS classification for seropositive APS (SP-APS) and 68 with clinical manifestations suggestive of APS but having negative serology, on 2 occasions, for criteria markers (SN-APS). On study inclusion, samples were retested for criteria and 11 non-criteria markers, including antiphosphatidylserine/prothrombin antibodies.

Results. Using 4 of 11 non-criteria tests, a cumulative $30.9 \%$ of SN-APS patients were detected. Combining results of all 11 non-criteria tests, 25 SN-APS (36.8\%) and 89 SP-APS (83.2\%) were positive for 1 or more non-criteria antibodies.

Conclusion. Failure to diagnose APS can result in severe clinical consequences. Patients displaying clinical features of APS, but negative for conventional criteria markers, should undergo additional testing for non-criteria biomarkers. In our cohort, around one-third of SN-APS patients showed reactivity to 1 or more non-criteria markers. An update to the current classification criteria incorporating new serological markers should be considered to identify and stratify patients with APS for more effective treatment and management. (First Release September 1 2017; J Rheumatol 2017;44:1597-602; doi:10.3899/jrheum.170044)

Key Indexing Terms:

ANTIPHOSPHOLIPID SYNDROME BIOMARKERS ANTIPHOSPHOLIPID ANTIBODIES AUTOIMMUNE DISEASES ANTIPHOSPHATIDYLSERINE/PROTHROMBIN ANTIBODIES

Growing recognition of the antiphospholipid syndrome (APS), an autoimmune condition described almost 30 years ago by Graham Hughes, has highlighted the need for accurate and effective diagnostic assays ${ }^{1}$. APS can lead to devastating clinical outcomes such as recurrent vascular thrombosis and pregnancy loss.
Based on the 2006 Sydney revision of the original 1999 Sapporo criteria, to be classified as having APS, laboratory testing should demonstrate the persistent presence of moderate to high $\mathrm{IgG} / \mathrm{IgM}$ anticardiolipin antibodies (aCL) and/or anti- $\beta_{2}$-glycoprotein I (anti- $\beta_{2}$-GPI) by ELISA and/or show, by a series of coagulation-based tests, lupus anticoag-
From Inova Diagnostics Inc., San Diego, California, USA; Academic Department of Vascular Surgery, King's College London; Graham Hughes Lupus Research Laboratory, Lupus Research Unit, The Rayne Institute, Division of Women's Health, King's College London, St. Thomas' Hospital, London, UK; Department of Internal Medicine, University of Castilla-La Mancha, Albacete, Spain; Department of Experimental Medicine, La Sapienza University, Rome, Italy.

Navid Zohoury, Zakera Shums, and Gary L. Norman are employees of Inova Diagnostics.

N. Zohoury, BS, Inova Diagnostics Inc.; M.L. Bertolaccini, PhD, Academic Department of Vascular Surgery, King's College London; J.L. Rodriguez-Garcia, PhD, Department of Internal Medicine, University of Castilla-La Mancha; Z. Shums, MSc, Inova Diagnostics Inc.;
O. Ateka-Barrutia, MD, Graham Hughes Lupus Research Laboratory, Lupus Research Unit, The Rayne Institute, Division of Women's Health, King's College London, St. Thomas' Hospital; M. Sorice, MD, Department of Experimental Medicine, La Sapienza University; G.L. Norman, PhD (AGAF, FAASLD), Inova Diagnostics Inc.; M. Khamashta, MD, PhD (FRCP), Graham Hughes Lupus Research Laboratory, Lupus Research Unit, The Rayne Institute, Division of Women's Health, King's College London, St. Thomas' Hospital.

Address correspondence to N. Zohoury, Inova Diagnostics Inc., 9900 Old Grove Road, San Diego, California 92131, USA.

E-mail:nzohoury@inovadx.com

Full Release Article. For details see Reprints and Permissions at jrheum.org Accepted for publication June 14, 2017.

Personal non-commercial use only. The Journal of Rheumatology Copyright @ 2017 . All rights reserved. 
ulant (LAC) positivity, on at least 2 occasions 12 weeks apart ${ }^{2,3,4,5}$. In addition to these laboratory criteria, patients suspected of APS must fulfill at least 1 of 2 clinical criteria: vascular thrombosis or pregnancy morbidity.

The finding of individuals who present a clinical picture highly suggestive of APS, but who are persistently negative for "criteria" antiphospholipid antibodies (aPL) has led physicians to refer to this patient population as having "seronegative" APS (SN-APS) ${ }^{6}$. While the use of the term remains a matter for debate, there is increasing recognition in the APS community of the existence of this subgroup $7,8,9,10,11,12$.

Several authors have suggested that testing for new aPL specificities may help to more clearly identify the syndrome in patients with thrombosis or pregnancy loss in whom APS is strongly suspected, but conventional aPL testing is repeatedly negative ${ }^{13,14,15}$. In our present study, using a highly characterized cohort of consecutive patients at St. Thomas' Hospital, London (a specialized tertiary-care center), we have evaluated a group of SN-APS patients with a series of "non-criteria" serological assays. We aimed to elucidate the antibody profile of SN-APS patients to assess the clinical utility of a group of candidate non-criteria markers [some available commercially and cleared for in vitro diagnostic use by the US Food and Drug Administration (FDA) and some assays only for research use that have not been subjected to strict regulatory review], and to suggest possible improvements to the classification criteria that would allow for more timely diagnosis of patients suspected of APS.

\section{MATERIALS AND METHODS}

Patients. A total of 175 patients were included in the study. Table 1 depicts clinical and laboratory characteristics of this cohort. Clinical characteristics of the majority of this patient population (154 out of 175) have been described previously in detail 7 . Briefly, consecutive patients with a suspected diagnosis of APS, who were attending the Louise Coote Lupus Unit at St. Thomas' Hospital, were categorized into 2 subgroups: 107 patients fulfilling the Sydney classification criteria for APS $^{2}$ (seropositive APS: SP-APS), and 68 patients with thrombosis and/or other major clinical manifestations suggestive of APS but persistently negative for $\mathrm{LAC}, \mathrm{IgG}$, and $\operatorname{IgM}$ aCL, and IgG and IgM anti- $\beta_{2}$-GPI, when tested on 2 separate occasions (SN-APS group).

This study was approved by the UK National Health Service National Research Ethics Service committee (London), under reference 10/H0715/001, and patients were enrolled after written consent was obtained. Patients with either clinical evidence or history of vasculitis were excluded from the study.

For inclusion into the study, all samples were tested for the presence of LAC by 2 screening tests and confirmed with both mixing and confirmatory tests as suggested by the current guidelines ${ }^{16}$. In addition to LAC, all patients were tested for $\operatorname{IgG}$ and $\operatorname{IgM} \mathrm{aCL}$ and anti- $\beta_{2}-\mathrm{GPI}$ as previously reported ${ }^{17,18}$. Patients fulfilling the Sydney criteria for APS were included in the SP-APS group. Patients fulfilling only clinical criteria but negative for criteria aPL were categorized as SN-APS and included in the SN-APS group.

On inclusion in the study, all samples were retested by commercially available and "research use only" assays. Commercially available tests included the following: IgA, IgG, and IgM QUANTA Lite aCL; IgA, IgG, and IgM anti- $\beta_{2}$-GPI; IgG and IgM antiphosphatidylserine (aPS); IgG and IgM antiphosphatidylserine/prothrombin complex (aPS/PT); and QUANTA
Flash anti- $\beta_{2}$-GPI Domain-I (DI) IgG. All these test materials are cleared by the FDA and manufactured by Inova Diagnostics Inc. Testing was performed blinded at Inova according to the manufacturer's instructions. The "research use only" tests included ELISA to detect IgG and IgM antiphosphatidylethanolamine antibodies (aPE) and $\mathrm{IgG}$ anti-cardiolipin/vimentin antibodies (aCL/Vim). Testing was done at the Lupus Research Unit, King's College London, for aPE and at the Department of Experimental Medicine at La Sapienza, Rome, for aCL/Vim, as previously described 19,20 .

Statistical analysis. Statistical analysis was performed using the Analyse-it software (Version 4.51; Analyse-it Software Ltd.). Testing for differences between SP-APS and SN-APS was done using Fisher's exact test with a 2 -tailed $\mathrm{p}$ value. A $\mathrm{p}$ value $<0.05$ was considered statistically significant.

\section{RESULTS}

Comparison of clinical characteristics of seronegative and seropositive individuals. The clinical characteristics of the SP-APS and the SN-APS patients were similar with a few exceptions. Thrombophilia was more frequent in the SN-APS population compared to SP-APS $(\mathrm{p}=0.036)$. Obstetric APS cases were also more prevalent in the SN-APS population $(p=0.036)$. Within the obstetric population, miscarriages were more frequently seen in SN-APS compared to SP-APS patients $(\mathrm{p}=0.021)$, while prematurity and preeclampsia showed no significant differences between the 2 groups (Table 1).

Detection of aPL. The prevalence of non-criteria aPL was higher in the SP-APS when compared to the SN-APS ( $\mathrm{p} \leq$ 0.0001 ; Table 2). Of the 107 SP-APS, only 3 samples showed no reactivity to at least 1 of 11 non-criteria aPL assays tested. On retesting the entire cohort with QUANTA Lite kits, 3 samples in the SN-APS group were each found to be low-positive for at least 1 criteria marker (IgG aCL, IgM aCL, or IgM anti- $\beta_{2}$-GPI).

Anti-PS/PT (IgG and/or IgM) was the most sensitive of the non-criteria biomarkers in the SP-APS group, detecting $60 / 107(56.1 \%)$ as positive. Figure 1 shows the presence and overlap of the non-criteria biomarkers in SP-APS (Figure 1A). Anti-CL/Vim IgG, aPS IgG/IgM, and aPE had similar sensitivity, being positive in 48 (44.8\%), $46(43 \%)$, and 44 $(41.1 \%)$ of the patients from the SP-APS group, respectively. The combination of the 4 non-criteria biomarkers was found in $87 / 107$ patients $(81.3 \%$ ) from the SP-APS group. In the SN-APS cohort, 8 samples tested positive for aPS/PT (4 IgG and $4 \mathrm{IgM} ; 11.8 \%), 4$ for aPS ( $3 \mathrm{IgG}$ and $1 \mathrm{IgM} ; 5.8 \%), 8$ for aPE (7 IgG only and 1 both IgG and IgM; $11.8 \%$ ), 11 for aCL/Vim IgG (16.1\%), and 1 for IgA anti- $\beta_{2}$-GPI (1.5\%; Figure $1 \mathrm{~B}$; note that IgA anti- $\beta_{2}$-GPI is not included in Figure 1). Combining the results of the non-criteria assays resulted in detection of $24 / 68$ patients $(36.8 \%)$ of the SN-APS as positive. While anti- $\beta_{2}$-GPI DI IgG was not found in any of the SN-APS, it was positive in 29/107 (27.1\%) of the SP-APS patients.

Relationship of aPS/PT antibodies to LAC. LAC was positive in $71 / 107(66.3 \%)$ of the SP-APS patients. Of the LAC-positive patients, IgG and/or IgM aPS/PT were present in 50 of the $71(70.4 \%)$ LAC-positive specimens. Using only

Personal non-commercial use only. The Journal of Rheumatology Copyright $\odot$ 2017. All rights reserved 
Table 1. Demographics and clinical characteristics of the study population.

\begin{tabular}{lccccc}
\hline \multirow{2}{*}{ Characteristics } & \multicolumn{2}{c}{ SP-APS } & \multicolumn{2}{c}{ SN-APS } & $\mathrm{p}$ \\
& $\mathrm{n}=107$ & $\%$ & $\mathrm{n}=68$ & $\%$ & - \\
\hline Age, yrs, mean (SD) & $46.2(11.1)$ & - & $45.8(9.3)$ & - & - \\
Sex (female) & 99 & 92.5 & 67 & 98.5 & - \\
VT & 47 & 43.9 & 27 & 39.7 & - \\
DVT & 31 & 28.9 & 21 & 30.8 & - \\
PE & 30 & 28.0 & 16 & 23.5 & - \\
AT & 39 & 36.4 & 24 & 35.2 & - \\
Stroke & 18 & 16.8 & 10 & 14.7 & - \\
TIA & 16 & 14.9 & 9 & 13.2 & 0.036 \\
CAD & 4 & 3.7 & 6 & 8.8 & - \\
Thrombophilia tested & $22^{*}$ & 20.6 & $24^{+}$ & 35.2 & 0.036 \\
Positive & $3 / 22^{* *}$ & 13.6 & $2 / 24^{++}$ & 8.3 & 0.021 \\
Pregnancy morbidity & $73 / 87$ & 83.9 & $62 / 65$ & 95.3 & - \\
Miscarriage & 42 & 48.2 & 44 & 67.6 & - \\
Prematurity & 20 & 22.9 & 19 & 29.2 & 27.6 \\
Preeclampsia & 24 & 27.5 & 18 & 2 & \\
\hline
\end{tabular}

*8 VT, 1 AT, 6 VT + AT. **1 Factor V Leiden heterozygous, 1 Protein S heterozygous, 1 unknown (all 3 VT only). ${ }^{+} 11$ VT, 4 AT, 5 VT + AT. ${ }^{++}$Both Factor V Leiden heterozygous (both VT only). Pregnancy morbidity was calculated over the total number of women who have ever been pregnant $(n=87$ for the SP-APS and 65 for the SN-APS groups). Only $\mathrm{p}$ values $<0.1$ are shown and values $<0.05$ are considered statistically significant. APS: antiphospholipid syndrome; SP-APS: seropositive APS; SN-APS: seronegative APS; VT: venous thrombosis; AT: arterial thrombosis; DVT: deep vein thrombosis; PE: pulmonary embolism; TIA: transient ischemic attack; CAD: carotid artery disease.

Table 2. Prevalence of aPL in SP-APS and SN-APS.

\begin{tabular}{lccccc}
\hline \multirow{2}{*}{ aPL } & \multicolumn{2}{c}{ SP-APS } & \multicolumn{2}{c}{ SN-APS } \\
& & $\mathrm{n}=107$ & $\%$ & $\mathrm{n}=68$ & $\%$ \\
\hline \multirow{2}{*}{ aCL } & IgG & 33 & 30.8 & 1 & 1.5 \\
& IgM & 20 & 18.7 & 1 & 1.5 \\
& IgA & 10 & 9.3 & 0 & 0.0 \\
Anti- $\beta_{2}$-GPI & IgG & 28 & 26.2 & 0 & 0.0 \\
& IgM & 25 & 23.4 & 1 & 1.5 \\
& IgA & 24 & 22.4 & 1 & 1.5 \\
Anti- $\beta_{2}$-GPI DI & IgG & 29 & 27.1 & 0 & 0.0 \\
aPS & IgG & 46 & 43.0 & 3 & 4.4 \\
& IgM & 13 & 12.1 & 1 & 1.5 \\
& IgA & 3 & 2.8 & 0 & 0.0 \\
aPS/PT & IgG & 44 & 41.1 & 4 & 5.9 \\
& IgM & 38 & 35.5 & 4 & 5.9 \\
aPE & IgG & 25 & 23.4 & 8 & 11.8 \\
& IgM & 27 & 25.2 & 1 & 1.5 \\
aCL/Vim & IgG & 48 & 44.8 & 11 & 16.2 \\
& & & & & \\
\hline
\end{tabular}

Single reactivity against noncriteria marker was seen in 19/25 aPL positive SN-APS samples (3 IgG and $3 \mathrm{IgM}$ aPS/PT, 1 IgG aPS, $5 \mathrm{IgG}$ aPE, and 7 IgG aCL/Vim). aPL: antiphospholipid antibodies; APS: antiphospholipid syndrome; SP-APS: seropositive APS; SN-APS: seronegative APS; aCL: anticardiolipin antibodies; anti- $\beta_{2}$-GPI: anti- $\beta_{2}$-glycoprotein I; DI: DomainI; aPE: antibodies to phosphatidylethanolamine; aCL/Vim: anticardiolipin/ vimentin antibodies; aPS/PT: antiphosphatidylserine/prothrombin antibodies; aPS: antibodies to phosphatidylserine.

the results of anti- $\beta_{2}$-GPI IgG/IgM, aCL IgG/IgM, and PS/PT $\mathrm{IgG} / \mathrm{IgM}$ (all FDA-cleared kits available for clinical laboratory use), 78/107 (72.9\%) of the SP-APS patients were detected. The combination of LAC, anti- $\beta_{2}$-GPI IgG/IgM, and aPS/PT IgG/IgM only, as suggested by Sciascia, et a ${ }^{21}$ as having the best diagnostic accuracy in their study, detected $95 / 107(88.9 \%)$ of the SP-APS and 8/68 (11.8\%) of the SN-APS patients.

\section{DISCUSSION}

In clinical practice, $\mathrm{aCL}$ and anti- $\beta_{2}$-GPI detected by ELISA and the LAC detected by clotting assays are the most widely used tests for the detection of aPL in patients suspected of having APS. However, despite the use of these assays for decades, standardization of aCL and correct determination of LAC still remain issues of ongoing concern. Further, in addition to LAC being a highly technical and demanding assay, anticoagulation treatment can interfere with its accurate detection, often resulting in false positives ${ }^{22}$. Because patients experiencing a thrombotic event are usually started on anticoagulant therapy immediately, this precludes accurate measurement of $\mathrm{LAC}^{23}$. Even when these tests function optimally, however, it is clear that these criteria tests miss a number of patients who present with the typical clinical features of APS, including multiple pregnancy losses and/or thrombotic events. Recognition of this subset of patients has prompted the concept of seronegative APS and has resulted in a continuing search for new specific markers. Identification and adoption of new markers could help reduce the number of so-called seronegative samples. While the commercial availability of new tests detecting non-criteria aPL has expanded over the past few years to include a variety of antibodies directed to phospholipid-binding proteins or their complexes with phospholipids, their incorporation into

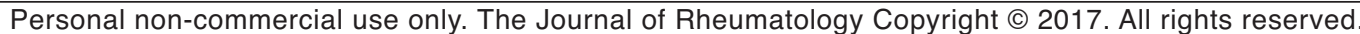


A

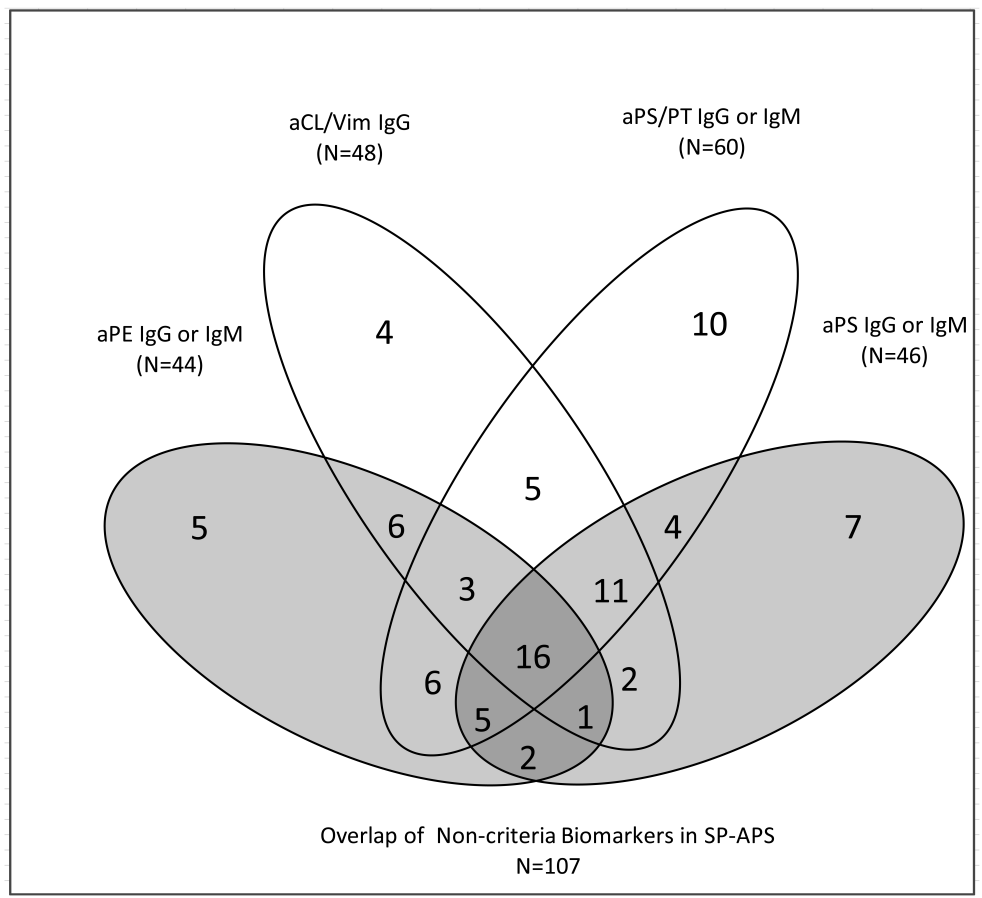

B

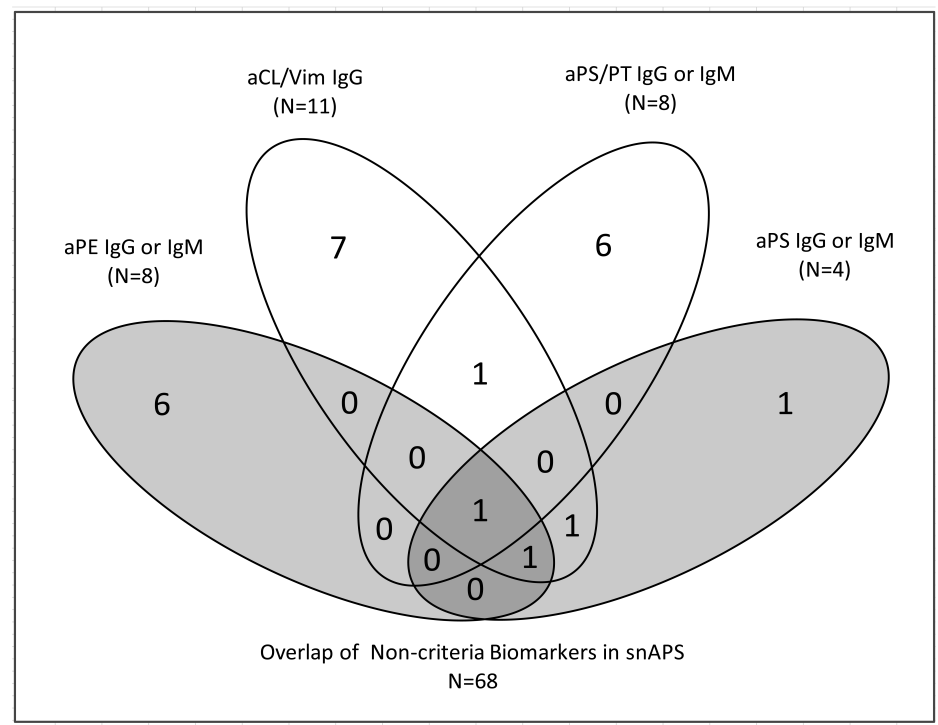

Figure 1. The distribution of non-criteria aPL biomarker reactivity in (A) SP-APS samples and (B) SN-APS samples. aPL: antiphospholipid antibodies; APS: antiphospholipid syndrome; SP-APS: seropositive APS; SN-APS: seronegative APS; aPE: antibodies to phosphatidylethanolamine; aCL/Vim: anticardiolipin/vimentin antibodies; aPS/PT: antiphosphatidylserine/prothrombin antibodies; aPS: antibodies to phosphatidylserine.

routine clinical practice has remained slow as a result of unclear clinical performance, as well as their "non-criteria" status.

Previously we described the clinical manifestations seen in the set of SN-APS patients analyzed here and compared their characteristics with a subset of patients fulfilling the Sydney clinical and laboratory criteria for definite $\mathrm{APS}^{7}$. In this study, we have expanded this cohort and clearly demonstrate that a significant subset of this SN-APS population $(36.8 \%)$ shows positivity for other antibodies to various 
phospholipid or phospholipid-binding proteins. Our results suggest that routine testing of criteria markers in patients displaying clinical features of APS should be supplemented by simultaneous or followup testing with additional assays that identify APS patients negative for these regular tests. In support of this concept, the task force at the 2010 International APS Congress in Brazil recommended that testing for aCL IgA, anti- $\beta_{2}$-GPI IgA, aPS/PT IgG, and aPS/PT IgM should be considered in any patient with a high suspicion of APS, but who is negative for the criteria markers ${ }^{15}$. The finding of aPS/PT IgG/IgM in $56.1 \%$ of the SP-APS also supports its inclusion as a major diagnostic biomarker of APS. In addition to its diagnostic value, aPS/PT also adds clinical value as a risk marker for thrombosis and has been associated with adverse outcome in patients with transient ischemic attack $^{23,24,25}$. Increasing evidence supports the utility of anti- $\beta_{2}$-GPI DI IgG as a risk marker for thrombosis ${ }^{26,27}$. In our study, $27.1 \%$ of the SP-APS, but none of the SN-APS cases, were anti- $\beta_{2}$-GPI DI IgG-positive. The lack of anti- $\beta_{2}$-GPI DI IgG in the SN-APS is not surprising, however, because by definition this group is anti- $\beta_{2}$-GPI IgG-negative.

While our study suggests the potential value of aCL/VIM and $\mathrm{aPE}$ as additional biomarkers for APS, the data supporting these markers at present is considerably weaker than that on aPS/PT. Assays for aPL antibodies are technically considerably more demanding to manufacture and control than many other conventional assays. In contrast to aPS/PT, which is commercially available and has been evaluated in a recent international multicenter study and subjected to rigorous FDA review, the other assays are less standardized and need additional studies, especially to validate their specificity using disease controls ${ }^{28}$. In our study, aCL/Vim antibodies were detected in $44.9 \%$ of the SP-APS patients and in $16.2 \%$ of the SN-APS patients, suggesting a potential utility. While this assay has proven difficult to translate from the research laboratory to commercial production for regulatory clearance, ongoing efforts are focused on overcoming this problem. LAC, when done by experienced laboratory workers, is a very useful and specific assay. It is, however, also technically very demanding, and as discussed above, the results are often unreliable when patients have received anticoagulant treatment. While aPS/PT does not detect all LAC-positive specimens and, therefore, is not a replacement for LAC testing, in our study it identified 41/71 (57.7\%) of LAC-positive cases. Other studies have reported up to $86.7 \%$ of the LAC-positive specimens were aPS/PT-positive ${ }^{23}$. These findings would suggest that when LAC is not available, aPS/PT could help in identifying patients who otherwise would be missed. Further, unlike LAC, aPS/PT is unaffected by anticoagulation treatment and thus provides a particularly valuable marker for anticoagulated patients ${ }^{24}$. In addition to its close association with LAC, aPS/PT also complemented LAC determination in our study, being positive in 18 of 35 (51.4\%) of LAC-negative SP-APS cohort and in 27/104 (26\%) of the entire combined SP-APS and SN-APS cohort. When LAC was combined with anti- $\beta_{2}$-GPI and aPS/PT in our current study, $88.9 \%$ of the SP-APS patients were detected.

In addition to new biomarkers, future updates to the APS classification criteria may incorporate methods of scoring patients based on their total antibody profile and clinical manifestations, rather than the current limited number of diagnostic assays. Two such systems that are based on testing a profile of antibodies and providing an algorithm for scoring the patient's antibody profile have been proposed; namely, the Global Anti-Phospholipid Syndrome Score (GAPSS) and the antiphospholipid score (aPL-S) ${ }^{29,30}$. A number of secondary studies have verified the usefulness of each of these respective approaches and the task force in 2014 suggested there is clinical utility in assessing multiple aPL positivity $31,32,33,34,35$. Notably, both the GAPSS and the aPL-S scoring systems require the specific measurement of aPS/PT antibodies (not antiprothrombin in solid phase-aPT) in addition to the criteria markers of LAC, aCL, and anti- $\beta_{2}$-GPI antibodies.

The use of new diagnostic algorithms and new biomarkers to supplement those developed many years ago will help the accurate and timely diagnosis of more patients with APS who are serologically negative for the current criteria markers and who therefore may be at risk of serious clinical consequences owing to delayed treatment. Such algorithms can also guide clinical laboratories in developing appropriate and efficient testing regimens tailored to their respective patient populations and available resources. This will benefit patients, as well as result in reduced healthcare spending, by reducing devastating and costly events such as thrombosis and pregnancy complications. It is expected that as technologies and our understanding of APS further evolve, these scoring systems will be updated, refined, and their utility validated in additional clinical studies. The evolution and adoption of new well-characterized markers and new scoring tools present the opportunity to move the field forward for the benefit of patients and the clinicians who care for them.

\section{REFERENCES}

1. Hughes GR. Thrombosis, abortion, cerebral disease, and the lupus anticoagulant. BMJ 1983;287:1088-9.

2. Miyakis S, Lockshin MD, Atsumi T, Branch DW, Brey RL, Cervera $\mathrm{R}$, et al. International consensus statement on an update of the classification criteria for definite antiphospholipid syndrome (APS). J Thromb Haemost 2006;4:295-306.

3. Adams M. Measurement of lupus anticoagulants: an update on quality in laboratory testing. Semin Thromb Hemost 2013; 39:267-71.

4. Lockshin MD, Sammaritano LR, Schwartzman S. Validation of the Sapporo criteria for antiphospholipid syndrome. Arthritis Rheum 2000;43:440-3.

5. Branch DW, Khamashta MA. Antiphospholipid syndrome: obstetric diagnosis, management, and controversies. Obstet Gynecol 2003;101:1333-4. Personal non-commercial use only. The Journal of Rheumatology Copyright (C) 2017. All rights reserved. 
6. Hughes GR, Khamashta MA. Seronegative antiphospholipid syndrome. Ann Rheum Dis 2003;62:1127.

7. Rodriguez-Garcia JL, Bertolaccini ML, Cuadrado MJ, Sanna G, Ateku-Barrutia O, Khmashta MA. Clinical manifestations of antiphospholipid syndrome (APS) with and without antiphospholipid antibodies (the so-called "seronegative APS"). Ann Rheum Dis 2012;71:242-4.

8. Lazurova I, Macejova Z, Tomkova Z, Remenar F, Boor A, Lazur J, et al. Severe limb necrosis: primary thrombotic microangiopathy or "seronegative" catastrophic antiphospholipid syndrome? A diagnostic dilemma. Clin Rheumatol 2007;26:1737-40.

9. Sanmarco M. Clinical significance of antiphosphatidylethanolamine antibodies in the so-called "seronegative antiphospholipid syndrome”. Autoimmun Rev 2009;9:90-2.

10. Cervera R, Conti F, Doria A, Iaccarino L, Valesini G. Does seronegative antiphospholipid syndrome really exist? Autoimmun Rev 2012;11:581-4.

11. Greaves M. Antiphospholipid syndrome: unusual clinical presentations. Thromb Res 2011;127 Suppl:S47-50.

12. Roggenbuck D, Egerer K, von Landenberg P, Hiermann R, Feist E, Burmester G, et al. Antiphospholipid antibody profiling: time for a new technical approach? Autoimmun Rev 2012;11:821-6.

13. Bertolaccini ML, Gomez S, Pareja JF, Theodoridou A, Sanna G, Hughes GR, et al. Antiphospholipid antibody tests: spreading the net. Ann Rheum Dis 2005;64:1639-43.

14. Alessandri C, Conti F, Pendolino M, Mancini R, Valesini G. New autoantigens in the antiphospholipid syndrome. Autoimmun Rev 2011;10:609-16.

15. Bertolaccini ML, Amengual O, Atsumi T, Binder WL, deLaat B, Forestiero R, et al. "Non-criteria" aPL tests: report of a task force and preconference workshop at the 13th International Congress on Antiphospholipid Antibodies, Galveston, TX, USA, April 2010. Lupus 2011;20:191-205

16. Pengo V, Tripodi A, Reber G, Rand J, Ortel L, Galli M, et al. Update of the guidelines for lupus anticoagulant detection. J Thromb Haemost 2009;7:1737-40.

17. Harris EN, Gharavi AE, Patel SP, Hughes GR. Evaluation of the anti-cardiolipin antibody test: report of an international workshop held 4 April 1986. Clin Exp Immunol 1987;68:215-22.

18. Amengual O, Atsumi T, Khamashta MA, Koike T, Hughes GR. Specificity of ELISA for antibody to beta 2-glycoprotein I in patients with antiphospholipid syndrome. Br J Rheumatol 1996;35:1239-43.

19. Bertolaccini ML, Murru V, Sciascia S, Sanna G, Khmashta MA. The clinical value of testing for antibodies to phosphatidylethanolamine (aPE) in patients with systemic lupus erythematosus (SLE). Thromb Res 2012;130:914-8.

20. Ortona E, Capozzi A, Colasanti T, Conti F, Alessandri C, Longo A, et al. Vimentin/cardiolipin complex as a new antigenic target of the antiphospholipid syndrome. Blood 2010;116:2960-7.

21. Sciascia S, Murru, Sanna G, Roccatello D, Khamashta MA, Bertolaccini ML. Clinical accuracy for diagnosis of antiphospholipid syndrome in systemic lupus erythematosus evaluation of 23 possible combinations of antiphospholipid antibody specificities. J Thromb Hemost 2012;10:2512-8.

22. Chighizola CB, Raschi E, Banzato A, Orgghi MO, Pengo V, Meroni
PL. The challenges of lupus anticoagulants. Expert Rev Hematol 2016;9:389-400.

23. Bertolaccini ML, Sciascia S, Murru V, Garcia-Fernandez C, Sanna $\mathrm{G}$, Khamashta M. Antibodies to phosphatidylserine/prothrombin (aPS/PT) are an independent risk factor for thrombosis in patients with systemic lupus erythematosus (SLE). Arthritis Rheum 2011;63 Suppl 10:S9.

24. Pregnolato F, Chighizola CB, Encabo S, Shums Z, Norman GL, Tripodi A, et al. Anti-phosphatidylserine/prothrombin antibodies: an additional diagnostic marker for APS? Immunol Res 2013;56:432-8

25. Mullen MT, Messé SR, Kasner SE, Sansing L, Husain MR, Norman GL, et al. Anti-phosphatidylserine-prothrombin antibodies are associated with outcome in a TIA cohort. Front Neurol 2012;3:1-5.

26. Mahler M, Norman GL, Meroni PL, Khamashta MA. Autoantibodies to domain 1 of beta 2 glycoprotein 1: a promising candidate biomarker for risk management in antiphospholipid syndrome. Autoimmun Rev 2012;12:313-7.

27. Mahler M, Albesa R, Zohoury N, Bertolaccini ML, Ateka-Barrutia $\mathrm{O}$, Rodriguez-Garcia JL, et al. Autoantibodies to domain 1 of beta 2 glycoprotein I determined using a novel chemiluminescence immunoassay demonstrate association with thrombosis in patients with antiphospholipid syndrome. Lupus 2016;25:911-6.

28. Amengual O, Forastiero R, Sugiura-Ogasawara M, Otomo K, Oku $\mathrm{K}$, Favas C, et al. Evaluation of phosphatidylserine-dependent antiprothrombin antibody testing for the diagnosis of antiphospholipid syndrome: results of an international multicentre study. Lupus 2017;26:266-76.

29. Sciascia S, Sanna G, Murru V, Roccatello D, Khamashta MA, Bertolaccini ML. GAPSS: the Global Anti-Phospholipid Syndrome Score. Rheumatology 2013;52:1397-403.

30. Otomo K, Atsumi T, Amengual O, Fujieda Y, Kato M, Oku K, et al. Efficacy of the antiphospholipid score for the diagnosis of antiphospholipid syndrome and its predictive value for thrombotic events. Arthritis Rheum 2012;64:504-12.

31. Mondejar R, González-Rodríguez C, Toyos-Sáenz de Miera FJ, Melguizo-Madrid E, Zohoury N, Mahler M, et al. Role of antiphospholipid score and anti- $\beta 2$-glycoprotein I Domain I autoantibodies in the diagnosis of antiphospholipid syndrome. Clin Chim Acta 2014;431:174-8.

32. Sciascia S, Bertolaccini ML, Roccatello D, Khamashta MA. Independent validation of the antiphospholipid score for the diagnosis of antiphospholipid syndrome. Ann Rheum Dis 2013;72:142-3.

33. Sciascia S, Cuadrado MJ, Sanna G, Murru S, Roccatello D, Khamashta MA, et al. Thrombotic risk assessment in systemic lupus erythematosus: validation of the Global Antiphospholipid Syndrome Score (GAPSS) in a prospective cohort. Arthritis Care Res 2014;66:1915-20.

34. Zuily S, de Laat B, Mohamed S, Kelchtermans H, Shums Z, Albesa $\mathrm{R}$, et al. Validity of the global anti-phospholipid syndrome score to predict thrombosis: a prospective multicentre cohort study. Rheumatology 2015;54:2071-5.

35. De Jesus GR, Agmon-Levin N, Andrade CA, Andreoli L, Chighizola CB, Porter TF, et al. 14th International Congress on Antiphospholipid Antibodies Task Force report on obstetric antiphospholipid syndrome. Autoimmun Rev 2014;13:795-813. 